Recebido: 10/03/2015

Aprovado: 17/08/2015

\title{
São João del-Rei, Ouro Preto e o uso simbólico dos conjurados na imprensa política: 1877 a 1889
}

Augusto Henrique Assis Resende*

Resumo: Este texto toca em pontos relativos à história econômica, social e política de Minas Gerais durante parte do período colonial e imperial. Por ele, tenta-se demonstrar que Minas não sofreu grandes abalos com o esgotamento do ouro, ocorrido na segunda metade do século XVIII, pois contava com uma economia diversificada e que conseguiu suprir a Capitania, posteriormente Província, de modo a deixá-la com uma situação em que era uma das mais importantes do centro-sul brasileiro. Outro enfoque abordado é o da importância que os jornais partidários tiveram nas Gerais. Por meio deles, discutia-se e se fazia política. Propagandeava-se e também se impunha tipos de apropriação e representação de figuras míticas atreladas à história mineira.

Palavras-chave: Imprensa; Minas Gerais; Brasil; História; Conjuração Mineira; 1789.

\begin{abstract}
This article is related to some points of economic, social and political history of Minas Gerais during part of the colonial and Imperial period. Then we try to show that the crises of the mining of gold, in the second half of seventh century, could not reach Minas totally because of the variety in its economy. Despite this, another important thing which we wrote was about the political journals in Minas Gerais. Those journals talked on political things and his practicing. With them, was imposed an appropriation and representation of mythic figures connected with the history of Minas Gerais.
\end{abstract}

Keywords: Press; Minas Gerais. Brazil; History; Conjuração Mineira; 1789.

\footnotetext{
* Licenciado e bacharel em História pela Universidade Federal de São João del-Rei (UFSJ). Mestre pela Faculdade de Ciências e Letras da Universidade Estadual Paulista (FCL/UNESP Assis). E-mail para contato: agtresende@oi.com.br
} 
Desde o início do século XVII, muitos bandeirantes paulistas, também chamados de sertanistas, partiam principalmente de São Paulo e de Taubaté em busca de riquezas minerais nos sertões brasileiros. Algumas das entradas empreendidas por esses bandeirantes eram oficiais, com cartas régias da Coroa portuguesa que os incentivavam a este fim; e outras tantas semioficiais. A Coroa prometia prêmios e honrarias aos sertanistas que descobrissem metais preciosos. Dessa maneira ocorreram muitas explorações em fins do século XVII nos sertões mineiros. Diversos sertanistas “[...] devassaram o interior, abriram caminhos, prepararam a descoberta do ouro a partir do século XVIII, em Minas Gerais [...]”. Várias dessas entradas que levavam ao sertão mineiro convergiam de São Paulo de Piratininga e eram rotas que muitos bandeirantes percorriam em busca de tesouros lendários (HOLANDA, 1989: 294).

Com a descoberta de ouro em diversos pontos do território que em poucos anos viria se tornar a Capitania de Minas Gerais, já na primeira década do século XVIII, quase todo o interior de Minas era conhecido. Com a mineração se estabelecendo foi iniciado o processo de povoamento, mas não só nas Gerais, pois a procura por novas áreas para a expansão nunca cessava. Vale assinalar também que,

[...] quer partindo de Taubaté, quer da vila de São Paulo, a verdade é que as bandeiras paulistas penetraram fundo pelo território mineiro, estabelecendo de início três pontos principais de atividade mineradora: no Rio das Mortes, tendo por centro São João del-Rei; na região de Ouro Preto e Mariana, e na área do Rio das Velhas, assinalada por Sabará e pela sua vizinha Caeté. Em torno desses três centros, numerosos outros povoados se foram estabelecendo [...] (HOLANDA, 1989: 297).

Mas mesmo que as antigas e rústicas picadas que os bandeirantes usavam para adentrar o território mineiro tenham se tornado estradas, ainda em período adiantado do século XVIII era preciso vencer muitos obstáculos naturais para se chegar à Capitania de Minas Gerais. Desde a costa fluminense, um dos locais mais usados para tal fim, o viajante que atravessasse a baía de Guanabara se deparava com a Serra do Mar, que resguardava o território mineiro, seguido ainda pelo fosso do vale do Rio Paraíba e pelas montanhas da Serra da Mantiqueira. Somado ao relevo da região que compunha a fronteira entre as Capitanias do Rio de Janeiro e de Minas Gerais havia densas florestas e caminhos que dificultavam o acesso às principais vilas mineiras. Para se fazer a ligação da cidade do Rio de Janeiro, sede do vicereinado português, à Vila Rica eram necessários cerca de 15 dias de viagem em caravana de mulas (MAXWELL, 1978). 
De acordo com dados censitários, que nem sempre são exatos devido a grandeza do território e aos perigos ao se cruzar as regiões habitadas por indígenas "selvagens", a população de Minas Gerais em 1776 ultrapassava os 300 mil habitantes, excluindo-se os índios, e se constituía na maior aglomeração de pessoas da América portuguesa. Os centros urbanos mais consideráveis, e os primeiros a serem estabelecidos na Capitania estavam relativamente próximos uns dos outros e se compunham por São João del-Rei ao sul, Sabará e Tijuco ao norte, e Vila Rica um pouco mais ao centro. Não obstante o número considerável de habitantes, essa população estava distribuída esparsamente pelo território mineiro e era classificada pelos censitários a partir de seus grupos raciais (MAXWELL, 1978).

Entre 1720 e 1815, Minas Gerais era composta por quatro comarcas: Rio das Velhas, Serro Frio, Vila Rica e Rio das Mortes. Cada uma destas comarcas tinha características bem diferentes quanto à formação de sua população, havendo muita variação na distribuição da parcela de brancos e negros - libertos ou escravos -, assim como nas "vocações" econômicas. A comarca do Rio das Velhas, cuja sede era Sabará, tinha muitas fazendas de gado e contava com alguns pontos de mineração. Era a comarca mais densamente povoada, tendo poucos brancos e grande quantidade de negros. A comarca de Serro Frio, com a Vila do Príncipe sendo seu centro mais importante, contava ainda com o Distrito Diamantino. Esta comarca tinha menos pessoas que as demais pelo tratamento acurado que a Coroa portuguesa tinha em relação aos diamantes dali extraídos. A comarca de Vila Rica e sua sede homônima era majoritariamente ligada à mineração e tinha grande quantidade de escravos. A comarca do Rio das Mortes, encabeçada por São João del-Rei, era povoada pelo maior número de brancos da Capitania, e tinha "[...] uma economia local mais equilibrada e diversificada" (MAXWELL, 1978: 109-110).

No entanto, a partir da década de 1770 houve ainda mais variabilidade na distribuição da população dentro da Capitania. Por meio de migrações internas, a comarca de Vila Rica começava a apresentar um decréscimo em sua população, que engrossava o conjunto de habitantes de outra comarca, a do Rio das Mortes. Esta comarca, localizada ao sul de Minas, fazia divisa com o Rio de Janeiro e São Paulo, e além da atividade mineradora bastante presente nas vilas de São João del-Rei e São José del-Rei, desenvolvia atividades nos ramos agrícola e pecuário. Esse movimento migratório acompanhou o declínio ocorrido na mineração do ouro na região de Vila Rica, já que era esta a atividade principal na comarca. Essa mudança seguia a alteração econômica que se veria em Minas Gerais depois daquela década. Uma economia que era majoritariamente pautada na mineração gradativamente 
penderia para um equilíbrio, não tendo mais a dependência de um nicho econômico específico. Porém, mesmo com a mineração sendo sucessivamente superada pelas atividades agropastoris com a proximidade do fim dos setecentos, uma atividade não excluía a outra, o que gerava notável diversificação econômica na região (MAXWELL, 1978: 110). Apesar de remontar a um período pouco anterior a 1770, essa diversificação econômica em Minas também ficou evidenciada pela datação de cartas de sesmarias do período de 1700-1750, em que se percebe a existência do plantio de roças de milho, feijão, mandioca e a criação de animais; que demonstram o convívio de atividades agropastoris com as de mineração mesmo antes de esta entrar em colapso (GRAÇA FILHO, 2004: 19-20).

No tocante à questão econômica mineira é interessante que teçamos algumas considerações, já que é um tema que há muito desperta a atenção de parte da historiografia. Por volta de meados do século XVIII, quando a extração do ouro ficou mais difícil e onerosa, passando a demandar técnicas mais elaboradas e investimentos mais vultosos, a consequência direta disso foi o quase abandono da atividade mineradora na Capitania de Minas Gerais. Segundo a visão de alguns estudiosos, a queda dessa produtividade levou a Capitania a uma situação bastante complicada, já que como acreditam, para que o foco na extração aurífera não fosse posto de lado ou diminuído, ações para o desenvolvimento da agricultura e pecuária foram desencorajadas. Assim, com as atenções voltadas apenas à mineração, quando esta entrou em crise, a economia da Capitania simplesmente teria quebrado.

Por outro lado, vemos uma linha historiográfica mais condizente com os fatos e os rastros, e que por meio de extensa pesquisa documental demonstrou que a decadência econômica de Minas Gerais em fins do século XVIII e em boa parte do XIX não passou de um mito. ${ }^{1}$ Um apontamento verificou que de 1828 a 1830, 48,5\% dos escravos recémchegados à costa do Rio de Janeiro foram importados por Minas Gerais. De acordo com registros do censo de 1872, considerado o mais completo realizado durante o período imperial, a Província de Minas tinha cerca de 300 mil habitantes. Uma região com economia debilitada não teria condições de manter uma população tão numerosa nem mesmo de comprar número tão grande de escravos. Naquele momento, Minas tinha um contingente

\footnotetext{
${ }^{1}$ Cf. FRAGOSO, João Luís Ribeiro. Homens de grossa aventura: acumulação e hierarquia na praça mercantil do Rio de Janeiro (1790-1830). Rio de Janeiro: Arquivo Nacional, 1992. GRAÇA FILHO, Afonso de Alencastro. A princesa do Oeste e o mito da decadência de Minas Gerais: São João del Rei (1831-1888). São Paulo: Annablume, 2002. GRAÇA FILHO, Afonso de Alencastro e LIBBY, Douglas Cole. A economia do Império Brasileiro. São Paulo: Atual Editora, 2004. MARTINS, Roberto Borges. Growing in silence: the slave economy os nineteenth-century Minas Gerais, Brazil. Vanderbilt University, 1980 (tese de doutorado). Os trabalhos historiográficos em questão comprovam o mito da decadência da econômica mineira.
} 
populacional superior ao das Províncias da Bahia e do Rio de Janeiro, que eram importantes zonas portuárias. Do mesmo modo, o número de escravos se elevava a patamares tão altos que contradizia que a escravaria mineira era decorrente apenas do crescimento endógeno (GRAÇA FILHO, 2004: 18-9). Outro estudo demonstrou que em período semelhante, mas que abrangeu de 1825 a 1833, da escravaria posta à venda no Rio de Janeiro, sua absorção por comerciantes mineiros foi de 48,4\%, “[...] porcentagem superior das áreas agroexportadoras do Vale do Paraíba e Norte Fluminense, que juntas receberam 36,5\% dessa mão-de-obra" (GRAÇA FILHO, 2002: 38).

A comarca do Rio das Mortes, uma das mais importantes de Minas Gerais no oitocentos, tinha grande importância para a Província. São João del-Rei, sede da comarca, era uma praça comercial que se destacava no comércio de alimentos produzidos no próprio município (vastíssimo), mas também com muitos deles vindos das comarcas do sul, oeste e noroeste mineiro - neste momento, já durante o Império, Minas Gerais contava não mais com as quatro comarcas iniciais, este número havia se elevado. O principal mercado para esses alimentos era a Corte, embora houvesse a comercialização com outras zonas (GRAÇA FILHO, 2004: 20). E já desde fins do setecentos, a comarca do Rio das Mortes dava mostras de sua dinamicidade econômica com uma produção acentuada de grãos, frutos do país e hortaliças, produtos usados em sua subsistência e que ainda provia a Capitania/Província de Minas Gerais de vários gêneros ligados à alimentação, como queijos, gados, carne de porco, etc. Condizente a esta comarca, mas direcionado à São João del-Rei, vemos que:

[...] a cessação da exploração aurífera não foi impedimento para a prosperidade do antigo arraial do Rio das Mortes, que continuava a abastecer toda a capitania com o fruto de suas atividades agrárias, pastoris e manufatureiras. O prosseguimento da situação afortunada da vila de São João del Rei, depois da idade do ouro, ficou lavrado na construção e acabamento de suas principais igrejas, finalizadas na primeira metade do século XIX (GRAÇA FILHO, 2002: 36).

Além disso, verificou-se que a atividade mineradora foi uma contingência na região de São João del-Rei. Assinala-se que desde que o bandeirante taubateano Tomé Portes del Rei, fundador do arraial em fins do século XVII, chegou à região já havia nela "fazendas de cultura e criação". Assim, com a diminuição da mineração, a vila retomou a atividade agropastoril de outrora. Mas ainda que fosse comum que um possuidor de lavras tivesse algumas roças contíguas àquelas, “[...] a extração aluvial do ouro só veio a diversificar ainda

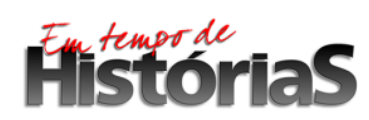


mais a estrutura produtiva da cidade, que viria a ser cognominada de 'Princesa do Oeste"" (GRAÇA FILHO, 2002: 36).

O acesso a São João del-Rei era um dos fatores que levaram ao desenvolvimento da vila, elevada à categoria de cidade em 1838. O Caminho novo, as estradas do Comércio e da Polícia serviam ao município são-joanense tanto na exportação quanto na importação de gêneros. Por essas vias, em algumas oportunidades, os comerciantes de São João del-Rei também faziam o escoamento da produção das Províncias de Goiás e de Mato Grosso. Outro fator favorável ao seu desenvolvimento foi sua localização, mais ao sul da Província mineira e próxima da fronteira com a Província do Rio de Janeiro. Devido a essa proximidade havia muitas relações comerciais entre as duas Províncias por meio desta cidade. Desta forma, dos 43 produtos exportados por Minas Gerais em 1818, 30 deles iam para o Rio. O mercado fluminense e da Corte eram tão importantes para os produtores mineiros que alguns exemplos dos produtos destinados àquele mercado devem ser exibidos: do gado vacum (78\%); porcos (49\%); queijos (57\%); tecidos de algodão (96\%); e toucinho (97\%). Mas o mercado mineiro também representava um atrativo aos comerciantes fluminenses, que faziam vendas significativas aos comerciantes de Minas, principalmente de sal, escravos, azeite, gêneros secos, ferramentas e vinhos (GRAÇA FILHO, 2002: 38-9).

Vemos ainda a importância que representou para Minas Gerais o seu incipiente desenvolvimento urbano, que destoava das outras partes do Brasil e proporcionava uma relação diferenciada entre as pessoas, mesmo que de estratos sociais diferentes, das vilas e cidades.

A província de Minas Gerais destacava-se na primeira metade do século XIX, em relação ao Império brasileiro. Tinha a maior população no Brasil da época. Usufruía a proximidade com a capital e com o porto do Rio de Janeiro, numa relação que remontava ao século da mineração e se fortalecera com a interiorização da Metrópole lusa. Herdara da expansão mineradora uma importante malha urbana, mostrando um relativo equilíbrio com o meio rural.

$[\ldots]$

A formação urbana difusa, incrustrada no interior, e as práticas administrativas, econômicas e culturais, sobretudo religiosas, que se mantiveram e se realimentaram na dinâmica da sociedade mineira oitocentista, tornaram peculiar a sociedade provincial de Minas. Era favorecida a circulação de ideias e, dentro das limitações da formação colonial, mais valorizada a educação escolar [...] (SILVA, 2009: 47-8).

Apesar de constatar que nas décadas de 1860 e 80 houve períodos de crise na região da comarca do Rio das Mortes, até 1861 São João del-Rei era o segundo município em 
arrecadação em Minas Gerais, só superado pela capital Ouro Preto. Porém, mesmo com alguns períodos de crises econômicas durante a segunda metade do século XIX, Graça Filho rechaçou qualquer alusão a uma decadência econômica, fosse em Minas Gerais ou em São João del-Rei (GRAÇA FILHO, 2002: 40-3).

Contudo, no correr da década de 1880 e na seguinte, a elite são-joanense remanescente de importantes famílias ligadas ao comércio de abastecimento interno tentou dinamizar ainda mais a economia do município, um pouco atingida pelas sucessivas instabilidades econômicas. Para isso, requisitou-se ao governo da Província o envio de imigrantes europeus à região para se incrementar as atividades agrícolas. Aventurou-se ainda no ramo industrial e fundou a Destilaria Castelo, em 1890, a Companhia Industrial Sanjoanense, em 1891, e as fábricas de cerveja Miller, de 1891, e Adriática, de 1892. Além de estabelecer uma ferrovia em 1878, denominada inicialmente Estrada de Ferro d'Oeste, e com mais da metade de seu capital arrecadado entre os são-joanenses via ações. Deste empreendimento ainda redundou a formação da Cia. Agrícola Industrial Oeste de Minas (GRAÇA FILHO, 2002: 47).

Foi apontado por Graça Filho e por relatos de viajantes que os grandes comerciantes, não apenas os que tinham registro na Real Junta de Comércio - já que esta prática nem sempre era seguida - procuravam distinção social por meio de títulos honoríficos. Em geral, esses comerciantes de São João del-Rei ostentavam patentes militares da milícia mineira ou da Guarda Nacional, como coronel, tenente-coronel, capitão. Todavia, alguns deles conseguiram galgar a distinções que proporcionavam ainda mais visibilidade na sociedade de então. Desta maneira, alguns dos mais proeminentes membros da sociedade são-joanense alcançaram os títulos da nobreza brasileira, o que evidencia que a "[...] apropriação de capitais pelo comércio sanjoanense foi um dos caminhos para o enobrecimento de algumas famílias" (GRAÇA FILHO, 2002: 60-5).

A acumulação de capitais proveniente de transações relacionadas ao comércio de abastecimento pode ter proporcionado o surgimento de um dos primeiros núcleos bancários brasileiros. Em 1822 foi criada uma caixa filial do Banco do Brasil na vila de São João delRei e, em 1860, foi fundada a casa bancária do coronel Custódio de Almeida Magalhães. Este capitalista, que ajudou na fundação da primeira fábrica têxtil da cidade, em 1891, havia herdado uma grande fortuna oriunda da acumulação mercantil e com a mineração (GRAÇA FILHO, 2002: 66 e 74).

Graça Filho expôs ainda que durante considerável parte do oitocentos, alguns dos grandes comerciantes de São João del-Rei, como em outras partes do Império também

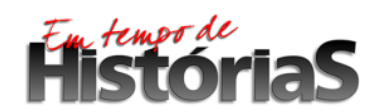


designados comerciantes de grosso trato, ${ }^{2}$ foram responsáveis por uma relevante circulação de capital na região. Não obstante, essa circulação se dava numa lógica mercantilista, onde o negociante-credor fornecia pequenos créditos a muitas pessoas e a prazos muito longos, que poderiam chegar a anos. Considerando que aquela sociedade não tinha uma elevada circularidade monetária, alguns dos clientes-devedores realizavam seus pagamentos por meio dos gêneros que produziam.

Através dos inventários post-mortem de muitos desses comerciantes, Graça Filho analisou que na maioria das vezes o montante mais expressivo do monte-mor do falecido fazia referência às dívidas ativas (empréstimos) e às dívidas em mercadorias. Segundo as análises deste historiador, essa prática era muito comum aos comerciantes são-joanenses e, condizente com o que assinalou, era também bastante lucrativa. Além disso, essa era outra forma de se sobressair socialmente, pois o credor alcançava poder e prestígio social (GRAÇA FILHO, 2002: 72-7).

Como pudemos notar, Minas Gerais e as duas cidades que mais nos interessam para o presente estudo, São João del-Rei e Ouro Preto, faziam parte de uma engrenagem bastante complexa em nível econômico. Vimos também que o fato de haver grande diversificação na economia proporcionava uma maior interação social, já que apesar de possuir a maior escravaria do Brasil, alguns trabalhos não eram realizados pela mão de obra servil, tornando o trabalho livre uma opção real. E como foi demonstrado, o sistema mercantil pré-capitalista propiciava o acesso ao crédito, fosse ele em espécie ou em mercadorias. Como um complemento aos aspectos socioeconômicos da sociedade mineira, mormente da são-joanense e da ouro-pretana, é com a política que encerraremos nossa análise sobre os mineiros em parte dos dois últimos decênios da monarquia brasileira. Pois o político e o social são indissociáveis, sendo o político o responsável pelo ordenamento social. Assim como a compreensão da sociedade não se resume aos aspectos sociais, culturais e econômicos. Visto que com o político, um agrupamento de pessoas é mais que uma população, é uma comunidade (ROSANVALLON, 2010).

Minas Gerais foi palco de muitos embates sociais ao longo de sua história. Todavia, o mais destacado deles ocorreu em fins do século XVIII e ficou conhecido como Inconfidência Mineira, ou mesmo Conjuração Mineira. Boa parte da questão econômica abordada acima tem relação direta com os conjurados mineiros, uma vez que muitos deles eram possuidores

\footnotetext{
${ }^{2}$ Os comerciantes mais notáveis nos oitocentos brasileiro, e que tinham transações mercantis em muitos ramos econômicos eram designados comerciantes grossistas ou de grosso trato.
} 
de lavras, proprietários de terras dedicadas à agricultura e tinham criação de gado. Muito se especula qual seria a finalidade do movimento de 1788-9, havendo quem acredite que mirava à liberdade de Minas Gerais; há os que creem que visava à independência do que atualmente se delineia como o Brasil; e os que julgam que os conjurados buscavam uma forma de a tributação portuguesa ser mitigada.

Ainda que até o presente momento não haja um consenso historiográfico relativo aos propósitos da Conjuração Mineira, a versão mais difundida dos fatos desde o fím do século XVIII, mas principalmente durante o XIX, foi a de que os inconfidentes planejavam a independência da América portuguesa. Apesar de não ser intuito nosso apurar esta questão, pois extrapola nosso objetivo, a crença mais corrente é a de que este movimento ocorrido no período colonial e inspirado na "revolução americana" estaria inserido numa corrente de acontecimentos que culminaram nos atritos e questões de interesses do reino do Brasil e da metrópole, o que redundou na independência política brasileira em 1822.

Em viagem pela Província de Minas Gerais em 1867, o viajante britânico Richard Francis Burton pôde ler alguns livros e apontamentos relativos a Minas Gerais e ouvir acerca das tradições contadas na Província, o que o levou a ter razões para acreditar que Joaquim José da Silva Xavier foi um dos defensores da independência da América portuguesa. Em passeio pela capital Ouro Preto, um dos pontos visitados pelo britânico foi a Rua de São José, na qual ficava a casa que Tiradentes viveu e que na década de 1870 já levava o nome do alferes. A respeito de Silva Xavier e do movimento de 1788-9, Burton pensava que "[...] Aquela casa nos traz à lembrança o tempo de um movimento popular, do qual esta grande e heróica Província tem razão de se sentir orgulhosa, por ele ser ligado diretamente à Independência do Brasil [...]”. Como veremos adiante não foi somente Burton que acreditava numa relação entre o movimento mineiro e o grito do Ipiranga. Continuou o viajante:

É evidente o caráter democrático da insurreição que o governo chamou de Conjuração ou Levante de Minas, e que hoje é conhecido popularmente como Inconfidência e tornou-se tão 'sagrado' como nossa Grande Rebelião. Os conspiradores [...] Tinham resolvido proclamar a independência e a liberdade e se propunham a abolir os odiados 'quintos' e outras extorsões reais; cancelar todas as dívidas da Coroa: abrir o proibido Distrito Diamantino e fundar uma universidade em Vila Rica e uma capital em São João del Rei. Tinham escolhido uma bandeira e as armas [...] Evidentemente, a intenção dos inconfidentes, em sua 'embrionária tentativa', era estabelecer uma república em Minas e nas capitanias vizinhas. Isso aconteceu em 1788 [...] (BURTON, 1976: 290).

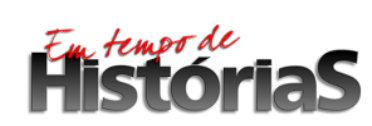


Burton não teve acesso a uma bibliografia muito rica do ponto de vista historiográfico - como exemplo, a primeira obra historiográfica a tratar do tema foi a História da conjuração mineira, de Joaquim Norberto de Sousa e Silva, e que só foi publicada seis anos após a estada de Burton em Minas Gerais. Ademais contava muito com os relatos orais, os quais, no caso da história da Inconfidência, havia o agravante do apagar de muitos rastros pela passagem do tempo. Mas deve ser ressaltado que é extremamente relevante a existência de farto material de cunho oral encontrado pelo viajante britânico mesmo depois de tanta repressão da Coroa portuguesa e pelos longos anos decorridos desde então.

Todavia, para esquadrinhar melhor os aspectos políticos no decorrer do oitocentos mineiro, nós lançaremos mão de um artifício que acreditamos ser suficiente para abordar de maneira satisfatória, embora não o único modo, o contexto político do fim do século XIX. Por meio da pesquisa em jornais são-joanenses e ouro-pretanos ligados aos partidos políticos, tencionamos visualizar e entender a apropriação e a representação que eram feitos relativamente aos conjurados mineiros. Apesar de nosso trabalho estar imerso metodologicamente no que se convencionou chamar de nova história política, usaremos esses dois conceitos, muito usuais na história cultural empreendida pelo historiador Roger Chartier. Em sua esteira, pretendemos estabelecer que a apropriação, em nosso caso feita a partir de textos jornalísticos, deu-se num contexto em que a produção deles era voltada para o propósito de enaltecer as figuras dos conjurados mineiros e, assim, agregar a este imaginário um elemento legitimador. Deste modo, a “[...] apropriação tal como a entendemos visa uma história social dos usos e das interpretações, relacionados às suas determinações fundamentais e inscritos nas práticas específicas que os produzem [...]" (CHARTIER, 2002: 68). Entendemos que a apropriação que a elite política e intelectual brasileira fez dos inconfidentes durante o período abarcado pela pesquisa, objetivava à construção de um mundo social aonde se moldasse as identidades coletivas com a finalidade de se impor uma autoridade, legitimar projetos (CHARTIER, 1990). É por isso que em certos momentos os conjurados foram objeto de disputas entre monarquistas e republicanos. E é igualmente importante sinalizarmos com o fato de que essas representações não estavam inseridas apenas no plano das ideias daquelas pessoas, elas se compunham de configurações tão reais quanto qualquer objeto, pois “[...] uma representação coletiva, por exemplo, em sua qualidade de representação, existe e é tão real quanto uma cadeira, um campo cultivado ou uma sinfonia [...]” (CARDOSO, 2012).

Além disso, Chartier entrou numa questão interessante concernente ao conceito de representação. Baseado no pensamento de Louis Marin, disse que foram apresentadas duas 
modalidades de representação que existiam há muito tempo, desde seus antigos significados, apontados pelo Dictionnaire de Furetière, em 1727. O primeiro sentido de representação apontava que ela passava a ideia de uma imagem que pintava os objetos tais como eles eram, isto é, materializava-se algo ou alguém que estava ausente, fosse por meio de imagens, palavras ou gestos. No entanto é dito que há uma distinção radical entre o representante e o representado, sendo preciso que haja um postulado que mostre e explique o signo, visível, e seu significante. Já o segundo sentido de representação a coloca como a demonstração de uma presença, a apresentação de uma coisa ou pessoa. Contudo, Chartier expôs que a proposição de Marin em manter juntos os dois sentidos de representação foi a decisão mais acertada (CHARTIER, 2002: 165-7). Cremos que os dois sentidos de representação citados acima foram utilizados para se caracterizar os conjurados mineiros. A variação entre a utilização do primeiro ou do segundo sentido se deu de acordo com o contexto e necessidade do momento, assim como de quem se valeu daquele uso.

E para a realização desse estudo pesquisamos seis jornais, sendo três de São João delRei e três de Ouro Preto. O Arauto de Minas (Conservador), que foi editado de 17 de março de 1877 a 24 de dezembro de 1889 - teve ainda um espaço de tempo em que o artigo definido foi retirado do título do jornal. Seu proprietário e redator principal era o professor sãojoanense Severiano Nunes Cardozo de Rezende, e por um período teve como editor-gerente Antônio Patrício de Paula Fonseca. A Patria Mineira (Republicano), cujo período de existência foi de abril de 1889 a maio de 1894 e tinha como redator chefe o também professor Sebastião Rodrigues Sette Câmara. E A Verdade Politica (Liberal), que perdurou de setembro de 1888 a dezembro de 1889, cujo redator responsável era Carlos Sanzio de Avellar Brotéro depois de um tempo o artigo definido também foi excluído do título do jornal.

Ademais, outra cidade que contava ter diversos periódicos era Ouro Preto, dos quais utilizaremos A Provincia de Minas (Conservador), que funcionou de 1878 a novembro de 1889 e tinha como sócios: Pedro Maria da Silva Brandão e José Pedro Xavier da Veiga. A Actualidade (Liberal), cujo primeiro número data de 16 de março de 1878 e vai até 29 de dezembro de 1881, que tinha por redator Carlos Alfonso de Assis Figueiredo. E o Liberal Mineiro (Liberal), que funcionou de 1882 a 1889 e era propriedade de Carlos Gabriel Andrade, passado em novembro de 1885 para Bernardo Pinto Monteiro.

Ambas as cidades tiveram um fluxo muito grande na produção de jornais desde o início do período monárquico, quando a imprensa era relativamente nova no país e, a partir de então quase sem cessar. A Província de Minas Gerais, encabeçada por Ouro Preto e São João

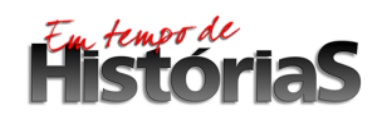


del-Rei respectivamente, teve dois momentos marcantes na imprensa, entre 1825 e 1842 , e a partir da década de 1870. Alex Lombello Amaral indicou que no primeiro recorte, mais de 60 jornais circularam em Minas, e que o apogeu desse periodismo se deu em 1831. Duas importantes folhas periódicas desta fase foram: O Universal (1825-1842) de Ouro Preto, ao que se sabe o primeiro jornal fundado em Minas Gerais; e O Astro de Minas (1827-1839), o primeiro a ser publicado em São João del-Rei. Pelo espaço cronológico em questão e a forma como os dois jornais atuaram, Amaral assinalou que o periodismo mineiro foi majoritariamente ligado à política. Explicou ainda que esse recorte cronológico, que coincide em sua maior parte com o período regencial, se deveu à ausência da figura do Imperador (AMARAL, 2008: 6-8).

Amaral apontou para a grande inconstância na produção jornalística em São João delRei, sem fazer uma análise para a capital mineira, no intervalo de tempo de três décadas, que decorreu do fim das publicações nos anos 1840 às dos anos 70. De acordo com o historiador em questão, no caso de São João del-Rei se nota ainda que muitos jornais atuantes nas décadas de 1870-80 - quando a imprensa foi retomada amplamente e com o auge em 1889 tinham relações estreitas com os três partidos: Conservador, Liberal e Republicano. Não obstante, a década de 1870, que já vira nascer muitos periódicos liberais em São João del-Rei, ainda não vislumbrara nenhum jornal ligado ao partido Conservador. Os muitos jornais liberais, com a inconstância em suas publicações e os curtos períodos de vida, podem apontar uma fragilidade, senão uma falta de organização do partido Liberal são-joanense. Contudo, deve ter sido pelo aparato político constituído pelo partido Conservador ao longo do Segundo Reinado, que não havia o interesse e a necessidade de se combater os liberais em São João del-Rei pelo meio jornalístico. Assim, os conservadores ainda não haviam se organizado para formar uma folha partidária. Foi somente em março de 1877 que tal passo fora dado (AMARAL, 2008: 6-8).

Principalmente a partir da década de 1870 muitas referências aos conjurados mineiros foram feitas nas páginas dos jornais mineiros. Os envolvidos na Conjuração Mineira eram há muito citados, comentados e representados pela literatura, livros de instrução, por alguns "clubs" e em casos isolados pela imprensa ao longo de todo o século XIX. Mas com a criação na Corte do partido Republicano, em 03 de dezembro de 1870, houve uma intensificação da apropriação dos conjurados. Em partes, isso se dava pelo momento político conturbado que o país atravessava, pois após a guerra contra o Paraguai, a monarquia foi sensivelmente abalada e passou a sofrer questionamentos cada vez mais fortes. Somadas às insatisfações decorrentes

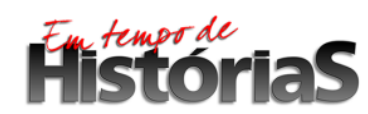


dessa guerra; as reformas do sistema eleitoral, como as de 1881 e 84; e leis que reviam ou amenizavam o sistema escravista, etc., o Imperador, uma das principais figuras do regime monárquico já não tinha a mesma vitalidade de anos anteriores, tendo em vista alguns problemas de saúde e a idade que começavam a se fazer sentir. Assim, não se tinha uma expectativa favorável à passagem do Segundo para o Terceiro Reinado (MORAIS, 1985, p. 63-74).

Com o fortalecimento dos republicanos crescia também o culto à imagem dos inconfidentes. Mesmo quando ainda eram organizados em alguns clubes ou imersos nas fileiras do partido Liberal, uma prática que foi comum, as pessoas de tendência e inspiração republicana já cultuavam o imaginário inconfidente num vislumbre de um futuro incerto. Para combaterem simbólica e ideologicamente o regime monárquico, os republicanos tinham que se apoiar em figuras com um forte apelo nacional e que proporcionassem a eles a legitimidade para um novo regime, um governo republicano pautado em tradições do passado nacional. Pois a imaginação é tida como uma ferramenta que acende paixões, e a tal imaginação se dirigem tipos de linguagens relativas a símbolos e emblemas. Estas linguagens seriam utilizadas como um aspecto fulcral no estabelecimento de uma educação pública calcada em ritos e festas cívicas (BACZKO, 1985: 300-1). No caso dos republicanos brasileiros, marginalizados institucionalmente, a educação não era uma atividade que pudesse ser facilmente alcançada, salvo quando eram professores, mas ainda assim com suas limitações. Porém, quanto aos ritos e festas cívicas, os partidários da República poderiam lograr êxito em atividades que poderiam pesar a seu favor - como em passeatas e discursos públicos.

Entretanto, a apropriação relativa aos conjurados mineiros não se restringia aos membros do partido Republicano nem aos simpatizantes da causa da República no Brasil. Os políticos monarquistas, fossem eles conservadores ou liberais, também lançaram mão do simbolismo inconfidente. Isso se tornou evidente nas páginas de alguns dos seus jornais, que podem ser apontados, por vezes, como a voz do partido em determinadas regiões. Assim como pelas páginas da Revista do Instituto Histórico e Geográfico Brasileiro, que em diversas oportunidades representou algum membro da conjura minera de 1788-9.

A busca e a apropriação de símbolos de um passado glorioso, que dessem suporte e autenticidade a governos vigentes e vindouros - pois se buscava nesse passado justamente elementos que garantissem estabilidade para o presente e até para o futuro - é essencial para se entender o jogo político do último quartel do século XIX. Para os monarquistas era fundamental se passar à ideia de que o legado dos conjurados - a busca pela liberdade de

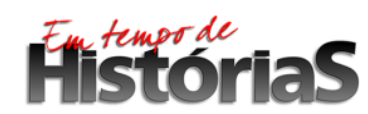


Minas e do Brasil - foi concretizado por D. Pedro I em 07 de Setembro de 1822. Mostrar uma sintonia entre as imagens de Tomás Antônio Gonzaga, Cláudio Manuel da Costa e outros conjurados, com a do primeiro Imperador do Brasil era indispensável para se dominar o imaginário social, algo significativo para quem detivesse o poder político.

Já os republicanos tentavam demonstrar, em sua luta pelo poder, que Joaquim José da Silva Xavier, o Tiradentes - e sua busca por liberdade - fora vítima da Coroa portuguesa com a sentença de 18 de abril de 1792, e que o governo Imperial brasileiro era a continuação do governo português, já que um membro da monarquia bragantina se encontrava no trono brasileiro. Isto é, os republicanos tentavam demostrar uma oposição clara entre Tiradentes e D. Pedro I para tentar enfraquecer o regime monárquico, já que fora este regime - quando o Brasil ainda era uma colônia - que frustrara a primeira tentativa de independência de um país que os partidários da República acreditavam ter vocação para ser republicano.

Ainda que a imagem dos inconfidentes estivesse presente entre a sociedade brasileira já há algumas décadas, foi, sobretudo a partir de 1881 que aspectos da política, ${ }^{3}$ da literatura e da imprensa mineira refletiam uma tendência nacional em que a Conjuração Mineira estava novamente enleada junto ao povo: fosse por meio da nomeação de lugares de memória, através de festividades, em forma de livros literários e de instrução, e pelas páginas da imprensa. O certo é que a memória inconfidente estava viva entre parte da população brasileira desde muito antes do advento da República, tendo a literatura, a história e a política, esta conjuntamente com a imprensa, importante papel na constituição desse fenômeno.

Ao longo do século XIX, alguns literatos ligados ao Romantismo usaram seu talento e suas penas para abordarem o tema Conjuração Mineira, ou algum de seus membros que tiveram mais relevo. Dentre os mais destacados literatos do período estavam Antônio Gonçalves Teixeira e Sousa, Castro Alves e Bernardo Guimarães. Teixeira e Sousa escreveu a obra Gonzaga ou a revolução do Tiradentes, publicada em duas edições (1848-51). Já com a obra Gonzaga ou a revolução de Minas, Castro Alves dedicou um título ao "Cristo da multidão", tendência que se concretizaria com o transcorrer do oitocentos. Enquanto Bernardo Guimarães se dedicou a escrever um capítulo de seu livro - História e Tradições da Província de Minas Gerais - que dizia respeito à cabeça do mártir mineiro, brasileiro (SERELLE, 2002).

\footnotetext{
${ }^{3} 1881$ foi o primeiro ano em que se comemorou - na cidade do Rio de Janeiro - publicamente a data de morte de Tiradentes como uma homenagem ao mártir da pátria brasileira.
} 
A difusão da história e das lendas ligadas aos conjurados mineiros já era perceptível, especialmente a partir da década de 1880, pois que ao longo dos anos, as publicações relativas à memória inconfidente aumentaram, e tal aumento pode estar atrelado à elevação do número nas comemorações cívicas, sobretudo as que aconteciam nas proximidades do dia 21 de abril. A imprensa teve papel decisivo na divulgação dos inconfidentes. Por meio de artigos editoriais ou em seções abertas a escritores diversos, os jornais mineiros divulgavam festividades, comentários, poemas e exaltações aos mineiros do movimento de 1788-9. Apesar de nosso enfoque estar atrelado aos seis jornais partidários de São João del-Rei e de Ouro Preto, em algumas edições desses jornais foi possível visualizar notícias de outros periódicos e que também eram relativas à história da Conjuração Mineira. Havia então, uma prática bastante comum de trocas de gentilezas e informações, onde algumas tipografias enviavam suas edições a outras tipografias e recebiam destas, os seus exemplares.

Isso pode ser exemplificado pela citação d'O Arauto de Minas, folha conservadora de São João del-Rei, que passava por um recesso no início de 1882 - provavelmente pela posse de seu redator principal na Assembleia Provincial de Minas Gerais - e que fez com que o sexto ano do periódico se iniciasse apenas em 29 de abril daquele ano. Portanto, não houve tempo para se proceder à publicação de 21 de abril de 1882, data que começava a ter significativa simbologia no calendário nacional, especialmente no mineiro. Como de costume, os artigos que tratavam de Tiradentes se faziam presentes nas edições próximas ao dia de comemoração de sua morte, porém, no ano de 1882, isso não foi possível devido ao supracitado recesso. Desta maneira, o redator Severiano de Rezende transcreveu algumas linhas de uma publicação de um jornal paulista:

Nenhuma palavra foi escrita pela imprensa campineira no dia 21 do corrente, nonagésimo aniversário do protomártir da liberdade brasileira, Joaquim José da Silva Xavier, vulto que se destaca com diamantino brilho e grandeza no cenário da nossa história política! Seria ingratidão? Seria esquecimento? Creio que foi só esquecimento.

Eu, filho da terra do mesmo berço de Tiradentes, confesso o meu pecado, esqueci [...] esse esplêndido sol de 21 de Abril de $1792 ! . .$.

Vou hoje ao correr da pena pagar um tributo à memória do legendário Mineiro com algumas palavras a respeito do seu nascimento e morte $[\ldots] .^{4}$

Não precisamos ir além, mas o autor do artigo - Dr. Cassiano - ainda transcreveu a sentença de morte do alferes Tiradentes e continuou a tecer elogios ao inconfidente punido pela Coroa

\footnotetext{
${ }^{4}$ O Arauto de Minas. Ano VI, n. ${ }^{\circ}$ 3, 14/05/1882, p. 3. São João del-Rei. Este artigo foi transcrito do Diário de Campinas e escrito pelo Dr. Cassiano.
} 
portuguesa. É interessante de se perceber o estranhamento notado pelo autor do artigo pela falta de homenagem ao "protomártir" Tiradentes em data aparentemente já comum para se proceder a isso. Em muitas outras edições d'O Arauto de Minas, observamos artigos escritos pelo Dr. Cassiano, o que ressalta a prática da correspondência entre um jornal e outro, além do fato do autor ser natural de São João del-Rei: “[...] Eu, filho da terra do mesmo berço de Tiradentes $[\ldots] "$ ".

Inclusive era usual em tais jornais haver um pequeno espaço para se publicar notas de agradecimentos às folhas que enviam seus exemplares. Isso fica evidenciado num segundo jornal, também alvo de nossas inquirições, o Liberal Mineiro, periódico liberal de Ouro Preto. Nele se vê a correspondência com outro órgão da imprensa onde se indicou o recebimento, da Corte, do Tiradentes, “[...] folha que, ha 7 annos, se publica em commemoração annual do grande martyr da liberdade. No numero com que fomos obsequiados, collaborarão diversos publicistas [...] Agradecemos". 5

Mesmo que tenha havido tentativas de se resgatar a imagem de Tiradentes na década de 1870, principalmente pelos clubes republicanos das Províncias do Rio de Janeiro e de Minas Gerais, deve ser observado que foi com o início dos anos 1880 que houve sucesso na promoção da memória inconfidente. Deve-se ressaltar que a primeira celebração concernente ao 21 de abril aconteceu na Corte, em 1881 (CARVALHO, 2001). E conforme analisamos nossas fontes, percebemos que com exceção dos anos de 1880 e 1887, em todos os outros anos daquele decênio houve publicações referentes aos conjurados de Minas, em especial sobre Tiradentes. No entanto, 1882 deve ter tido relevância ímpar para os defensores da memória dos conjurados, pois foi o ano que mais teve publicações nos jornais que diziam respeito à Conjuração Mineira e a Tiradentes. Consequentemente foi o ano que mais vimos mobilizações sociais em torno do imaginário inconfidente. Toda essa agitação social e política tinha um motivo plausível, visto que em 21 de abril de 1882 se completaram 90 anos da execução do inconfidente Joaquim José da Silva Xavier.

O excerto relacionado ao jornal da Corte, citado logo acima, também corrobora a importância do ano de 1882 no que toca às comemorações do aniversário de morte de Tiradentes, já que havia sete anos que tal jornal publicava edições referentes a este fim, como por nós foi destacado. Dos seis jornais que pesquisamos, três apresentam muitas menções ao aniversário de morte de Tiradentes, com artigos variados a esse respeito. Das edições 96 a 98

${ }^{5}$ Liberal Mineiro, ano XI, n. ${ }^{\text {2 } 29, ~ 25 / 04 / 1888, ~ O u r o ~ P r e t o, ~ p . ~ 3 . ~ M a n t i v e ~ a ~ p o n t u a c ̧ a ̃ o ~ e ~ a ~ o r t o g r a f i a ~ o r i g i n a i s . ~}$ Grifo nosso. 
d'A Provincia de Minas, ${ }^{6}$ órgão conservador de Ouro Preto, muito se fez para a divulgação dos festejos relativos ao 9. ${ }^{\circ}$ decenário de morte de Tiradentes. Como vemos na programação oficial:

Programma dos festejos do $9 .^{\circ}$ decennario de Tiradentes

Dia 20 de abril: Espetaculo em grande gala, que começará ás 8 horas da noute e logo após a chegada de S. Exc. O Sr. Dr. Presidente da Provincia por uma overtura e á grande orchestra intitulada Sonho da Independencia dividida em tres partes: - 1. ${ }^{a}$ Preludios; $2 .^{a}$ Canto do Martyr; 3. ${ }^{a}$ apotheose, [...] Em seguida será cantado o Hymno de Tiradentes [...] sendo a poesia do laureado poeta Bernardo Guimarães [...] Ao terminarem os discursos que serão proferidos pelos illustrados e sympathicos oradores - Dr. Henrique Salles, Xavier da Veiga e Antonio Olyntho, como representantes da imprensa e da comissão central, effectuar-se-ha a Apotheose do Proto-martyr da Independencia.

Dia 21 de abril: Ao romper d'alva haverá uma salva de 21 tiros no jardim da praça e será tocado o Hymno de Tiradentes pela banda marcial do corpo policial, que em seguida percorrerá as ruas da capital. [...]

Dia 22 de abril: A's 8 horas da noite será levado a scena pela 2. ${ }^{a}$ vez o mesmo drama Abençoadas Lagrimas! precedido da overtura - Sonho da Independencia [ ]. ${ }^{7}$

Em nota após o programa, a comissão responsável pelo evento esclareceu que teve poucos recursos financeiros frente às grandes despesas e pediu que o público comparecesse às peças teatrais como uma forma de ajudar financeiramente. Além disso, ressaltou o convite para que a população participasse da conferência que se realizaria no teatro da capital.

No editorial do número 97 d'A Provincia de Minas, o autor defendeu a utilização simbólica dos inconfidentes por qualquer partido político, não importando sua orientação. Além de descrever todas as atividades concernentes à comemoração ao 21 de abril, destacou também a importância dos conjurados mineiros para a história nacional, mas principalmente para a história dos mineiros:

Desde a noite do dia 20 do corrente até a de hontem, a população ouropretana, em actos sucessivos e imponentes, manifestou bella e eloquentemente os sentimentos patrioticos que a animão para com os vultos legendarios da historia patria, precursores illustres da liberdade e da independencia nacional.

O objeto das enthusiasticas manifestações foi a commemoração do $9 .^{\circ}$ decennario de Tiradentes, coração e alma da nobre e mallograda inconfidencia mineira, o mais ardente de seus adeptos e o mais gloriosos de seus martyres.

\footnotetext{
${ }^{6}$ Escrito como no original, sem o acento ortográfico.

${ }^{7}$ A Provincia de Minas, ano II (novo período), n. ${ }^{\circ}$ 96, 16/04/1882, Ouro Preto, p. 4. Mantive a ortografia original, embora tenha alterado um pouco a forma com que o texto foi montado, pois boa parte dele é centralizado, com título e subtítulos.
} 
Sem distincção de classes e matizes politicos - todos se associarão no elevado pensamento da patriotica commemoração.

Assim devia ser. A conjuração mineira de 1789 não reflecte o exclusivismo de uma escola partidaria, como á alguns espiritos menos reflectidos se afigura.

Sua bandeira foi a da - Independencia e da Liberdade - e a bandeira da patria, sob cuja sombra protectora se acolhem todos bons cidadãos. Tiradentes, Claudio Manoel, Gonzaga [...] e tantos outros benemeritos propugnadores do movimento emancipador, só ambicionavão, quebrando o [sic.] grilhões da escravidão colonial, construir para si e para seus conterraneos uma patria livre e independente.

Liberdade e independencia não são privilegios exclusivos de nenhum regimen politico. [...] A memoria dos patriotas mineiros de 1789 é e merece ser venerada por todos os homens livres, quaesquer que sejão as escolas políticas a que se filiem. ${ }^{8}$

Foi sublinhada a participação popular nos três dias de evento, sendo dito que houve grande concorrência do público para todos eles. É interessante que, além da participação das variadas classes sociais, foi salientado que o Estado também se fez presente nas festividades. Não só pelos seus altos funcionários, mas especialmente pela presença de Teófilo Otoni (filho), presidente da Província.

A presença de muitas pessoas nos eventos de 1882, assim como nos que se seguiram a esses, demonstra que o trabalho de apropriação feito a partir das imagens dos inconfidentes, somado à sua utilização simbólica naquela sociedade e feito de sua representação surtiu um efeito considerável então: conseguiu reunir pessoas de classes e segmentos políticos diversos ao redor de festividades que visavam laurear figuras míticas, saudosas do passado "nacional". E a participação de membros destacados do Estado mineiro nessas comemorações concernentes aos inconfidentes e, principalmente, ao alferes Tiradentes denota a relevância dada à Conjuração Mineira ainda no período monárquico. A história de uma Província que, segundo parte dos Homens que viveram no século XIX, assim como parte da historiografia do século XX foi a responsável por gestar os primeiros patriotas da América portuguesa: aqueles bacharéis, poetas, sacerdotes, militares, financistas e tantos outros que, talvez, tenham sido os primeiros a pensar num rompimento com a mãe-pátria na tentativa de se instalar uma república nos vastos territórios ultramarinos da Coroa portuguesa. Mas sejam esses fatos pertinentes ou não, o que importa ressaltar é que com a instalação da República em fins de 1889, vai mostrar o quanto a última década do século XIX foi decisiva na propagação do imaginário atrelado aos conjurados de Minas Gerais, tendo a imprensa relevante papel em

\footnotetext{
${ }^{8}$ A Provincia de Minas, ano II (novo período), n. ${ }^{\circ}$ 97, 24/04/1882, Ouro Preto, p. 1. Grifos do autor. Mantivemos a ortografia original do texto.
} 
personificar, por meio das representações em suas páginas, aqueles patriotas numa nova conjuntura política. E aqueles homens, principalmente Tiradentes, os quais se tornaram importantes ícones de uma mudança de mentalidade pela qual a sociedade brasileira precisava passar. Com novas definições acerca de seus fundadores enquanto nação e numa tentativa de legitimação e estruturação do Estado republicano.

\section{Referências bibliográficas}

\section{Fontes Primárias}

Os seis jornais pesquisados por nós são das cidades mineiras de Ouro Preto e de São João del-Rei. Podem ser consultados na biblioteca do campus Dom Bosco da Universidade Federal de São João del-Rei (UFSJ), microfilmados. Assim como, digitalizados, nos sítios eletrônicos do Arquivo Público Mineiro e da Hemeroteca Digital Brasileira da Fundação Biblioteca Nacional.

Os originais de alguns dos jornais se encontram na Biblioteca Municipal Batista Caetano de Almeida, em São João del-Rei. Porém, sem se poder consultá-los. Ainda assim, no arquivo da Casa do Pilar, em Ouro Preto, há uns poucos títulos.

\section{De Ouro Preto:}

A Actualidade (1878-1881).

O Liberal Mineiro (1882-1889).

A Provincia de Minas (1878-1889).

\section{De São João del-Rei:}

O Arauto de Minas (1877-1889).

A Verdade Politica (1888-1889).

A Patria Mineira (1889-1894).

\section{Fontes Secundárias}

AMARAL, Alex Lombello. Cascudos e chimangos: Imprensa e política pelas páginas dos periódicos de São João del-Rei (1876-1884). Dissertação - Programa de Pós-Graduação em História, Universidade Federal de Juiz de Fora, Juiz de Fora, 2008.

BACZKO, Bronislaw. “Imaginação social”. In. ROMANO, Ruggiero (org.) Enciclopédia Einaudi, Lisboa, 1985.

BURTON, Richard Francis, Sir. Viagem do Rio de Janeiro a Morro Velho. Belo Horizonte: Ed. Itatiaia; São Paulo: Ed. da Universidade de São Paulo, 1976. (Reconquista do Brasil, v. 36).

CARDOSO, Ciro Flamarion. "História e poder: uma nova política?" In: CARDOSO, Ciro Flamarion; VAINFAS, Ronaldo (org.). Novos domínios da história. Rio de Janeiro: Elsevier, 2012.

CARVAlHO, José Murilo de. A formação das almas: o imaginário da República no Brasil. São Paulo: Companhia das Letras, 11. reimpressão, 2001.

CHARTIER, Roger. À beira da falésia: a história entre incertezas e inquietudes. Porto Alegre: Ed. Universidade/UFRGS, 2002.

CHARTIER, Roger. A história cultural: entre práticas e representações. Lisboa/Rio de Janeiro: DIFEL/Bertrand Brasil, 1990.

GRAÇA FILHO, Afonso de Alencastro e LIBBY, Douglas Cole. A economia do Império Brasileiro. São Paulo: Atual Editora, 2004.

GRAÇA FILHO, Afonso de Alencastro. A princesa do Oeste e o mito da decadência de Minas Gerais: São João del Rei (1831-1888). São Paulo: Annablume, 2002. 
HOLANDA, Sérgio Buarque de (dir.). A época colonial: V.1 - Do descobrimento à expansão territorial. Rio de Janeiro: Bertrand Brasil, 1989.

MAXWELL, Kenneth. A devassa da devassa: a Inconfidência Mineira, Brasil - Portugal, 1750-1808. Rio de Janeiro: Paz e Terra, 1978.

MORAIS, Evaristo de. Da Monarquia para a República (1870-1889). Brasília: UnB, 1985.

ROSANVALlON, Pierre. Por uma história do político. São Paulo: Alameda, 2010.

SERELLE, Márcio de Vasconcellos. Os versos ou a história: a formação da Inconfidência Mineira no imaginário do Oitocentos. Tese de doutoramento apresentado ao Departamento de Teoria e História Literária do Instituto de Estudos da Linguagem da Universidade Estadual de Campinas. Campinas, 2002.

SILVA, Wlamir. Liberais e povo: a construção da hegemonia liberal-moderada na província de Minas Gerais (1830-1834). São Paulo: Editora Hucitec, 2009. 